\title{
Bladder perforation during laparoscopy detected by gaseous distention of the urinary bag -A report of two cases-
}

\author{
Jae Hee Woo, Guie Yong Lee, and Hee Jung Baik \\ Department of Anesthesiology and Pain Medicine, School of Medicine, Ewha Womans University Mokdong Hospital, Seoul, Korea
}

Bladder perforation during laparoscopy is a recognized, uncommon complication. We present two cases of bladder perforation during laparoscopic gynecologic operations that were detected by gaseous distention of the urinary bag. Bladder perforation occurred through laparoscopic division of adhesion. One bladder perforation was repaired laparoscopically, and the other case was repaired by laparotomy during the same general anesthesia. In this report, we present evidence that monitoring a gas-distended urinary bag during a laparoscopic procedure can help detect intraoperative bladder perforation. (Korean J Anesthesiol 2011; 60: 282-284)

Key Words: Bladder, Gaseous distention, Laparoscopy, Perforation, Urinary bag.

Laparoscopic gynecologic surgery has been described as an effective and safe procedure. It is associated with decreased morbidity and admission periods and is widely used in practice. However, regardless of these advantages, this procedure has its own potential for serious complications related to pneumoperitoneum, position change, and laparoscopic instrument. Traumatic complications due to instruments manipulation include bowel perforation, large vessel injury, gastric perforation, bladder perforation, and ureter injury. It is known that the incidence of bladder injury during laparoscopic procedures ranges from $0.02 \%$ to $8.3 \%$, and that the most common laparoscopic procedure during which bladder injury occurs is laparoscopic-assisted vaginal hysterectomy
[1]. Here, we report two cases of bladder perforation during laparoscopic gynecologic operations that were detected by gaseous distention of the urinary bag. In these two case reports, we emphasize that anesthesiologists can detect intraoperative complications and decrease in the possibility of postoperative peritonitis and laparotomy morbidity.

\section{Case Reports}

\section{Case 1}

A 39-year-old woman $161 \mathrm{~cm}$ tall weighing $51 \mathrm{~kg}$ was diagnosed with uterine myoma and an abdominal wall mass

Received: October 7, 2010. Revised: October 26, 2010. Accepted: November 25, 2010.

Corresponding author: Guie Yong Lee, M.D., Ph.D., Department of Anesthesiology and Pain Medicine, School of Medicine, Ewha Womans University Mokdong Hospital, 911-1, Mok-dong, Yangcheon-gu, Seoul 158-710, Korea. Tel: 82-2-2650-5040, Fax: 82-2-2655-2924, E-mail: lgyanes@ewha.ac.kr

(c) This is an open-access article distributed under the terms of the Creative Commons Attribution Non-Commercial License (http:// creativecommons.org/licenses/by-nc/3.0/), which permits unrestricted non-commercial use, distribution, and reproduction in any medium, provided the original work is properly cited. 
and scheduled for laparoscopic myomectomy. She had a benign thyroid nodule with normal thyroid function. The rest of her medical history was unremarkable. Preoperative blood tests, chest radiography, electrocardiogram, and vital signs were normal. She was premedicated with $2 \mathrm{mg}$ of midazolam and a $0.5 \mathrm{mg}$ atropine intramuscular injection 30 minutes before arrival to the operation room. Anesthesia was induced with $250 \mathrm{mg}$ thiopental sodium and $100 \mu \mathrm{g}$ fentanyl. The patient was intubated after receiving a $30 \mathrm{mg}$ rocuronium injection. Anesthesia was maintained with $\mathrm{N}_{2} \mathrm{O}-\mathrm{O}_{2}$-sevoflurane ( $1-2$ volume $\%)$. She was monitored intraoperatively by electrocardiography, non-invasive blood pressure, pulse oximetry, end-tidal capnography, sevoflurane concentration, and Bispectral Index (BIS; A-2000 ${ }^{\circledR}$, Aspect Medical System, Norwood, Massachusetts, USA).

The patient was placed in the lithotomy position. Carbon dioxide was injected into the peritoneal cavity via a veress needle until peritoneal pressure reach $12 \mathrm{mmHg}$. Myomectomy and adhesiolysis were performed because pelvic adhesion was shown via laparoscopy. Two hours after the operation was initiated, the anesthesiologist notified the surgeon of gaseous distention of the urinary bag which is filled with 150 $\mathrm{ml}$ of urine (Fig. 1). The surgeon tried to detect a perforation site by sight but failed to detect a bladder perforation. Urine leakage or hematuria was not observed in the operation field. Subsequently, the bladder was distended with $250 \mathrm{ml}$ of saline under cystoscopy after which a $0.7 \mathrm{~cm}$ hole in the dome of the bladder was discovered. Bladder repair was executed via a laparoscopic surgical technique. The vital signs of the patient were stable and the urine volume after bladder repair was $100 \mathrm{ml}$. She was discharged on postoperative day 9 with a foley catheter. The foley catheter was removed after there was no more urine leakage as determined by cystoscopy on

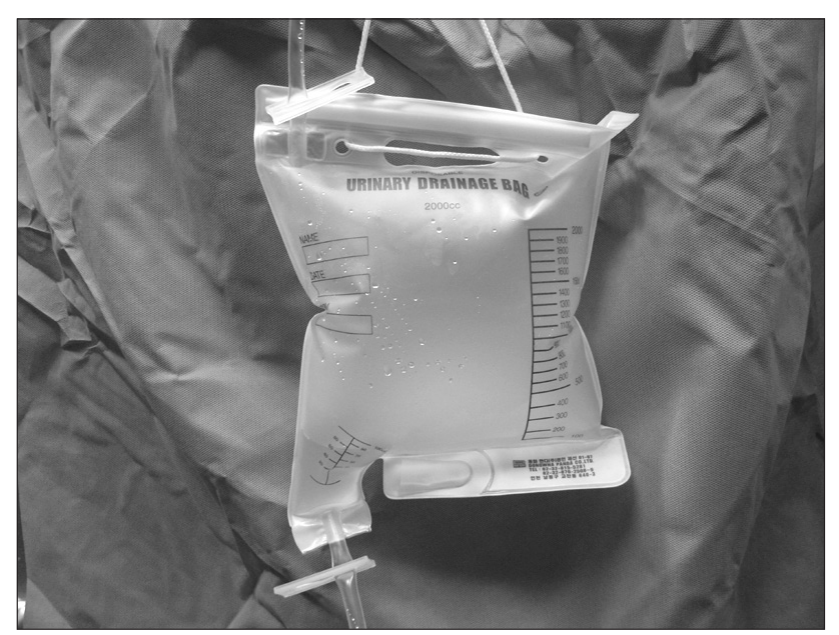

Fig. 1. Gaseous distention of the urinary bag. postoperative day 15 .

\section{Case 2}

A 45-year-old woman $159 \mathrm{~cm}$ tall and weighing $59 \mathrm{~kg}$ was diagnosed with endometrioma and scheduled for laparoscopicassisted vaginal hysterectomy. Her medical history was unremarkable. Preoperative blood tests, chest radiography, electrocardiogram, vital signs, and physical examination were normal. Premedication, anesthesia induction, maintenance, and monitoring were the same as Case 1. After the patient was placed in the lithotomy position, carbon dioxide was injected into the peritoneal cavity via a veress needle until peritoneal pressure reach $12 \mathrm{mmHg}$. Her bladder was observed to be tethered up on the uterus via laparoscopy. Marked gaseous distention of the urinary bag which was filled with $350 \mathrm{ml}$ was noticed 30 minutes after the operation started. Laparoscopy revealed a $1.5 \mathrm{~cm}$ hole in the dome of the bladder including the mucosa layer. Urine leakage or hematuria was not found. Bladder perforation was diagnosed with a conversion to a laparotomy. Total hysterectomy and bladder repair was performed. The urine volume after bladder repair was $150 \mathrm{ml}$. The vital signs were stable in the operation and recovery room. She discharged on postoperative day 5 with a foley catheter. The foley catheter was removed after there was no more urine leakage as determined by cystoscopy on postoperative day 13 .

\section{Discussion}

Bladder perforation is an uncommon complication of laparoscopic surgery. Since it was first reported, it has been noted to occur during procedures involving a verres needle, trocars (primary or secondary), and electrocautry regardless of improvements in surgical techniques and safety instructions [2]. Predisposing risk factors for complications during laparoscopic procedures include operation history of the patient, pelvic adhesion, endometriosis, obesity, urachal anomaly, and unskilled surgeons [3].

Bladder perforation during laparoscopic surgery may be detected by intraperitoneal bleeding, clear liquid in the operation field, hematuria, and gaseous distention of the urinary bag [4]. Among these, hematuria and gaseous distention of the urinary bag could be detected early by anesthesiologists. If hematuria is found intraoperatively or postoperatively, cystoscopy or cystoradiography can be used to confirm bladder perforation. Hematuria may not occur in all bladder perforation cases and there are difficulties in diagnosing intraoperatively [5]. Sia-Kho and Kelly [6] reported that they detected a gaseous distention of the urinary bag at the conclusion of laparoscopic adhesiolysis but ignored this, and that the patient complained 
of abdominal tenderness, nausea, and vomiting 4 hours after operation. Laparotomy was performed after bladder perforation was confirmed by cystoscopy and cystoradiography. They emphasized that gaseous distention of urinary bag is an initial sign of bladder perforation, and anesthesiologists should monitor the urinary bag. Subsequent cases have verified that observing the urinary bag is a reliable way to monitor bladder perforation [6-9].

Gaseous distention of the urinary bag due to bladder perforation indicates communication between bladder and intraperitoneal space. Because the volume of urinary bag commonly used in Korea is 2,000 ml, gaseous distention could reveal within 2,000 $\mathrm{ml}$ of total amount including urine and gas. When a urinary bag with air outlet is used, gaseous distention can occur because the diameter of the inlet for urine and gas is larger than that of the outlet for air. However, gaseous distention would not appear in an inelastic urinary bag, so carbon dioxide gas could be measured at the air outlet by mass spectroscope or infrared spectrometer when bladder perforation is suspected. Schanbacher et al. [7] detected $10 \%$ carbon dioxide at a urinary bag.

In our cases, it is thought that bladder perforation occured through laparoscopic dissection of severe adhesion of uterus with bladder despite no previous abdominal surgery. In Case 1, the urinary bag seemed to become distended gradually because the size of the bladder injury was small. In Case 2, the urinary bag was distended instantly because the size of the bladder injury was large. Therefore, the size of injury is likely to affect the time of gaseous distention presentation. Further studies about cause-and-effect relationship between peritoneal pressure, the size of injury, and gaseous distention of the urinary bag are needed. Early detection during laparoscopic surgery allows immediate bladder repair via laparoscopy or laparotomy and decreases postoperative morbidity. A small undetected tear may heal if bladder decompression is maintained, but may cause oliguria, peritonitis, and fistula formation [9]. Insertion of a foley catheter is associated with a risk of infection; on the other hand, this decreases the risk of bladder injury because it permits continuous decompression of bladder. It also allows early detection of bladder injury which is not found in the operation field, so insertion of indwelling foley catheter is recommended [5]. In conclusion, continuous monitoring of gaseous distention of the urinary bag should aid in the early detection of bladder perforation in patients with predisposing factors of bladder injury.

\section{References}

1. Ostrzenski A, Ostrzenska KM. Bladder injury during laparoscopic surgery. Obstet Gynecol Surv 1998; 53: 175-80.

2. Georgy FM, Fettermann HH, Chefetz MD. Complication of laparoscopy; two cases of perforated urinary bladder. Am J Obstet Gynecol 1974; 120: 1121-2.

3. Mirhashemi R, Harlow BL, Ginsburg ES, Signorello LB, Berkowitz R, Feldman S. Predicting risk of complications with gynecologic laparoscopic surgery. Obstet Gynecol 1998; 92: 327-31.

4. Font GE, Brill AI, Studhldreher PV, Rosenzweig BA. Endoscopic management of incidental cystotomy during operative laparoscopy. J Urol 1993; 149: 1130-1.

5. Lamaro VP, Brome JD, Vancaillie TG. Unrecognized bladder perforation during operative laparoscopy. J Am Assoc Gynecol Laparosc 2000; 7: 417-9.

6. Sia-Kho E, Kelly RE. Urinary drainage bag distention: An indication of bladder injury during laparoscopy. J Clin Anesth 1992; 4: 346-7.

7. Schanbacher PD, Rossi LJ Jr, Salem MR, Joseph NJ. Detection of urinary bladder perforation during laparoscopy by distention of the collection bag with carbon dioxide. Anesthesiology 1994; 80: 680-1.

8. Classi R, Sloan PA. Intraoperative detection of laparoscopic bladder injury. Can J Anaesth 1995; 42: 415-6.

9. Ho AM, Roth P, Cowan WD. Gaseous distention of the urinary bag indicating bladder perforation during laparoscopic pelvic procedures. Int J Gynaecol Obstet 1996; 55: 297-8. 